\title{
Metabolic regulation of exercise-induced angiogenesis
}

\author{
Tatiane Gorski and Katrien De Bock \\ Department of Health Sciences and Technology, Laboratory of Exercise and Health, Swiss Federal Institute of Technology (ETH) Zurich, Zurich, Switzerland
} Correspondence should be addressed to K De Bock: Katrien-debock@ethz.ch

\begin{abstract}
Skeletal muscle relies on an ingenious network of blood vessels, which ensures optimal oxygen and nutrient supply. An increase in muscle vascularization is an early adaptive event to exercise training, but the cellular and molecular mechanisms underlying exercise-induced blood vessel formation are not completely clear. In this review, we provide a concise overview on how exercise-induced alterations in muscle metabolism can evoke metabolic changes in endothelial cells (ECS) that drive muscle angiogenesis. In skeletal muscle, angiogenesis can occur via sprouting and splitting angiogenesis and is dependent on vascular endothelial growth factor (VEGF) signaling. In the resting muscle, VEGF levels are controlled by the estrogen-related receptor $\gamma(E R R \gamma)$. Upon exercise, the transcriptional coactivator peroxisome-proliferator-activated receptor- $\gamma$ coactivator- $1 \alpha$ (PGC1 $\alpha$ ) orchestrates several adaptations to endurance exercise within muscle fibers and simultaneously promotes transcriptional activation of Vegf expression and increased muscle capillary density. While ECs are highly glycolytic and change their metabolism during sprouting angiogenesis in development and disease, a similar role for EC metabolism in exercise-induced angiogenesis in skeletal muscle remains to be elucidated. Nonetheless, recent studies have illustrated the importance of endothelial hydrogen sulfide and sirtuin 1 (SIRT1) activity for exercise-induced angiogenesis, suggesting that EC metabolic reprogramming may be fundamental in this process. We hypothesize that the exerciseinduced angiogenic response can also be modulated by metabolic crosstalk between muscle and the endothelium. Defining the underlying molecular mechanisms responsible for skeletal muscle angiogenesis in response to exercise will yield valuable insight into metabolic regulation as well as the determinants of exercise performance.
\end{abstract}

\section{Introduction}

Skeletal muscle is a highly plastic organ which ensures locomotion and is critical for the maintenance of whole body metabolic homeostasis $(1,2)$. Oxygen, glucose and other nutrients are delivered to the muscle via an ingenious network of blood vessels formed by neatly aligned endothelial cells (ECs). During exercise, the uptake of oxygen and nutrients needs to increase dramatically

Key Words
- endothelial metabolism
- exercise
- angiogenesis
- metabolism
- microvasculature

microvasculature
$(3,4)$, and for this reason, blood flow through the vessels surrounding the active muscle fibers increases within seconds $(5,6,7)$. In response to repeated exercise bouts, the formation of new capillaries from existing ones, a highly dynamic and tightly controlled process termed angiogenesis, is initiated $(8,9)$. The increase in muscle vascularization is an early adaptive event to exercise 
training, occurring before or simultaneously with the switch in fiber types (10) or the increase in activity of oxidative enzymes in the myofibers $(11,12)$. Exercise is also the most effective non-surgical therapy to increase muscle angiogenesis and to ameliorate the symptoms of ischemia in peripheral artery disease $(13,14)$. An increase in muscle capillarity is expected to improve blood-tissue exchange properties by increasing the surface area for oxygen diffusion, nutrient uptake and/or elimination of toxic waste products, and therefore, should determine the metabolic potential of the muscle, a concept that was already recognized by August Krogh in the beginning of the 20th century (15). Nonetheless, despite the intimate link between capillary content and muscle metabolism, the molecular mechanisms underlying muscle angiogenesis in response to exercise are still poorly understood.

\section{Mechanisms of angiogenesis in skeletal muscle}

Angiogenesis can occur via distinct mechanisms: vessel sprouting or vessel splitting (also called intussusception or non-sprouting angiogenesis) (16). Vessel sprouting is initiated by the conversion of a quiescent EC into a tip cell, which sends out filopodia and guides a sprout in response to the secretion of pro-angiogenic factors from the hypoxic or metabolically active microenvironment (17). The neighboring cells become stalk cells that proliferate, extend the growing sprout and form a lumen (18). When two sprouts fuse, blood flow reinitiates and the ECs return to quiescence, secrete basement membrane components and form tight junctions (19). In skeletal muscle, only a few electron microscopy studies have observed capillary sprouts following chronic muscle electrostimulation $(20,21,22,23)$ or overload induced by synergist ablation $(23,24)$ in rodents or upon endurance training in humans (25). Moreover, while the molecular mechanisms that control vessel sprouting during development and certain diseases are widely studied $(26,27,28)$, evidence for a conserved program occurring in skeletal muscle in response to exercise training is lacking.

During vessel splitting, capillaries expand via the insertion of pillar-like structures into the vessel lumen $(16,29)$. A contact zone is formed between opposing capillary walls, followed by the perforation of the contact zone and shaping of a pillar-like structure. Ultimately, expansion of the pillar results in splitting of the primary vessel into two new ones. Vessel splitting may occur in the virtual absence of endothelial proliferation and can allow rapid expansion of a vascular network, which, in contrast to sprouting angiogenesis, does not require the breakdown of the extracellular matrix (30). Vessel splitting can be induced in the absence of muscle contractions by pharmacologically elevating blood flow $(23,24)$ or by chronic electrostimulation, in which contractions take place simultaneously to an increase in blood flow $(22,23)$. This suggests that sprouting and splitting angiogenesis could be complementary or additive phenomena in response to muscle contraction and can be dependent on the mode of contraction. Indeed, differences in the angiogenic response to exercise were reported between exercise programs involving concentric versus eccentric contractions in rats (31). Moreover, isometric and dynamic contractions differentially affect muscle blood flow and could therefore evoke a different angiogenic response (32). The temporal and spatial characteristics of sprouting versus splitting angiogenesis, as well as their relative contribution to the expansion of the vascular network in response to different exercise modes, are not clear and require further investigation.

The growth of functional capillaries following exercise is the result of a tight balance between pro- and anti-angiogenic factors, with the pro-angiogenic vascular endothelial growth factor (VEGF) playing a crucial role. Skeletal muscle VEGF mRNA (33) and protein (34) levels transiently increase after acute exercise bouts and VEGF is essential for exercise-induced angiogenesis (35, 36), though it is not clear whether this is by promoting splitting or sprouting angiogenesis. Even though VEGF is a powerful stimulator of sprouting angiogenesis (17), its overexpression by myoblasts implanted into skeletal muscle increases capillarity essentially via intussusception $(29,37)$. The VEGF levels in such model, however, are much higher than those observed upon exercise (29). Pharmacological inhibition of VEGF receptor signaling or deletion of Vegf in myofibers $(35,36,38)$ blunts but does not completely prevent the increase in capillary-to-fiber ratio following exercise training. Of note, since VEGF also promotes contraction-induced hyperemia (39), reduced capillary density following training upon myofiber-specific deletion of Vegf could be secondary to reduced blood flow. Moreover, under specific conditions such as muscle damage, other cells within the muscle microenvironment which localize in close proximity to capillaries express pro-angiogenic genes (40), but it remains to be shown whether activation of these cells during exercise can promote angiogenesis.

\section{Exercise-induced changes in metabolism of skeletal muscle cells promote angiogenesis}

It is clear that there is an intimate interplay between angiogenesis and metabolism in skeletal muscle.

This work is licensed under a Creative
Commons Attribution-NonCommercial 4.0
International License.


Indeed, slow-twitch, fatigue-resistant muscles are characterized by high capacity for energy production via oxidative phosphorylation (OXPHOS) and have a dense vascular network, while fast-twitch, fatigue-sensitive muscles display lower OXPHOS, higher capacity for glycolytic energy production and fewer capillaries (11, 41, $42)$. The estrogen-related receptor $\gamma(\operatorname{ERR} \gamma)$ is exclusively and abundantly expressed in slow muscle fibers, and activation of ERR $\gamma$ in fast muscle fibers increases OXPHOS and vascular density, as well as exercise endurance (43). ERR $\gamma$ controls baseline muscle vascularization by directly upregulating the expression of the Vegf and $F g f 1$ genes and by activating the energy sensor $5^{\prime}$ adenosine monophosphate-activated protein kinase (AMPK) (43), which also promotes Vegf transcription $(44,45)$. Accordingly, mice expressing a dominant negative AMPK in muscle have lower baseline capillarization, but do not show impairments in exerciseinduced angiogenesis (45), suggesting that different metabolic regulators control baseline versus exerciseinduced vascular density (Fig. 1).

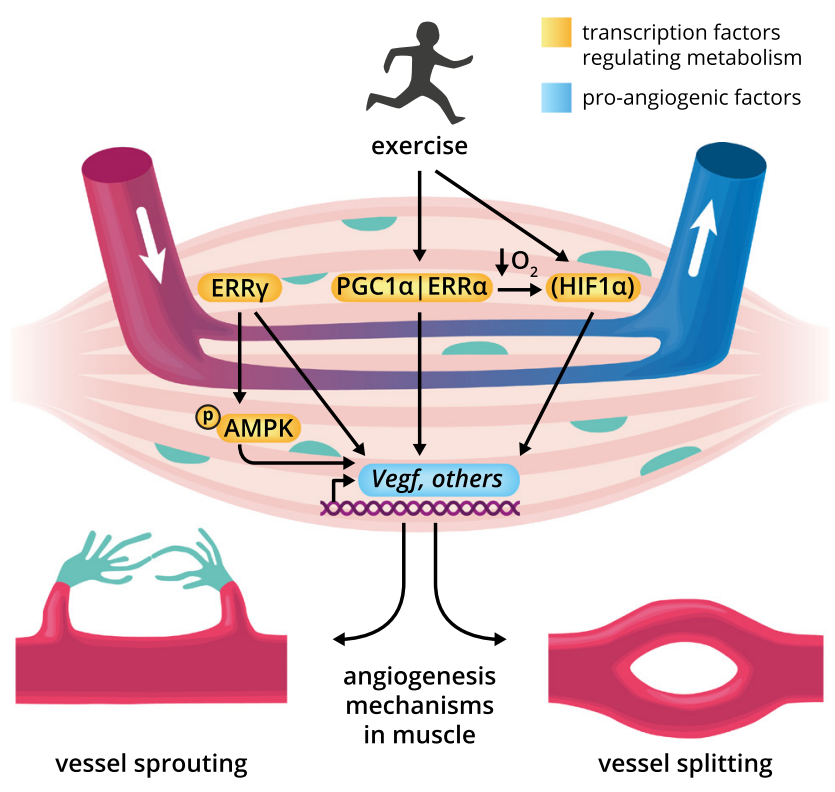

Figure 1

Exercise-induced activation of transcription factors in myofibers stimulates angiogenesis. While ERR $\gamma$ determines baseline muscle vascularization either via direct binding to the VEGF promoter or via controlling the activity of AMPK, exercise-induced activation of PGC $1 \alpha$ (through recruitment of ERR $\alpha$ to the VEGF promotor), and potentially increased stabilization of HIF1 $\alpha$, culminates in the increased expression of VEGF and other pro-angiogenic factors. Release of VEGF and other angiogenic factors from the exercising muscle leads to increased muscle vascularization through vessel sprouting or vessel splitting. AMPK, 5' adenosine monophosphate-activated protein kinase; ERR $\alpha$, estrogenrelated receptor $\alpha$; ERR $\gamma$, estrogen-related receptor $\gamma ; \mathrm{HIF} 1 \alpha$, hypoxia inducible factor $1 \alpha$; PGC $1 \alpha$, peroxisome-proliferator-activated receptor- $\gamma$ coactivator-1 $\alpha$; VEGF, vascular endothelial growth factor.
The transcriptional coactivator PGC1 $\alpha$ (peroxisomeproliferator-activated receptor- $\gamma$ coactivator- $1 \alpha$ ) is a potent metabolic sensor, which is activated during exercise $(46,47)$ and orchestrates several adaptations to endurance exercise including mitochondrial biogenesis and increased OXPHOS (48). PGC1 $\alpha$ also controls the expression of Vegf and other pro-angiogenic genes by recruiting estrogen-related receptor $\alpha(\operatorname{ERR} \alpha)$ to conserved binding sites within their promoters $(49,50)$. In contrast to Erry, loss of $P g c 1 \alpha$ does not affect baseline muscle capillary density $(43,51)$, but mice lacking Pgc1 $1 \alpha$ or Err in myofibers fail to increase vascular density in response to exercise $(50,52)$. Even though PGC1 $\alpha /$ ERR $\alpha$ control Vegf expression independently of hypoxia signaling via the hypoxia inducible factor (HIF) $1 \alpha$ (49), hypoxia increases PGC1 $\alpha$ gene expression (49, 53) and the $P g c 1 \alpha$-mediated increase in mitochondrial content can indirectly promote cellular hypoxia due to increased oxygen consumption (54). Nonetheless, the role of HIF1 $\alpha$ in regulating muscle angiogenesis is still controversial since muscle-specific loss of Hif1 $\alpha$ leads to a higher - not lower - capillary-to-fiber ratio (55).

\section{ECs metabolically rewire during angiogenesis}

ECs are highly glycolytic and produce $85 \%$ of their energy glycolytically (56). However, when they need to sprout into avascular areas, they upregulate glycolysis even further and reducing EC glycolysis by deleting the glycolytic regulators $P f k f b 3$ (phosphofructokinase-2/ frustcose-2,6-bisphosphatase isoform 3) or hexokinase 2 impairs EC migration and proliferation, resulting in impaired angiogenesis during development and under several pathological conditions $(56,57,58)$. Beyond ensuring optimal energy provision, glycolytic enzymes (such as the pyruvate kinase muscle isoenzyme PKM2) also prevent cell cycle arrest during angiogenesis (59). ECs do not require mitochondrial ATP production for angiogenesis, but rather use their mitochondria to maintain $\mathrm{NAD}^{+} / \mathrm{NADH}$ balance (60) and as a hub for macromolecule synthesis during proliferation. Indeed, fatty acid oxidation is crucial for the synthesis of nucleotides used in DNA replication, and blocking this process impairs EC proliferation without affecting migration (61). Interestingly, intermediates of lipid synthesis also control proliferation via posttranslational repression of the activity of the mechanistic target of rapamycin complex 1 (mTORC1), which controls cell growth (62). Proliferating ECs also consume high

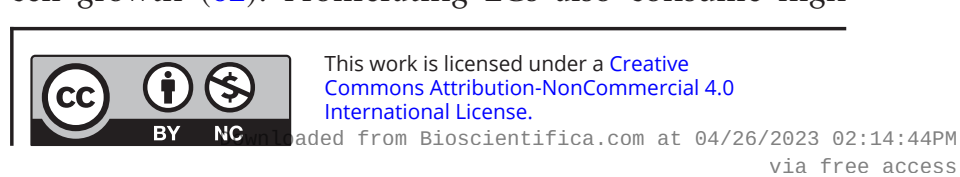


amounts of glutamine, and glutamine deprivation or deletion of glutaminase 1 decreases vessel sprouting due to decreases in both cell migration and proliferation $(63,64)$. A detailed overview of the metabolic regulation of EC function during sprouting is provided elsewhere $(65,66)$, but to the best of our knowledge, there are no studies showing that ECs also metabolically rewire during intussusception.

\section{Do ECs metabolically rewire during exercise- induced muscle angiogenesis?}

Only very few studies have addressed the role of skeletal muscle EC metabolism in response to exercise. Exerciseinduced angiogenesis requires adequate activation of the $\mathrm{NAD}^{+}$-dependent deacetylase sirtuin 1 (SIRT1) nutrient sensor in ECs (67), at least partially because endothelial Sirt1 is required for VEGF-mediated angiogenesis (67, 68). SIRT1 controls EC function by inhibiting Notch, a potent repressor of sprouting as well as intussusception $(69,70)$, and via deacetylating and inactivating forkhead box O1 (FOXO1) (69), which ensures endothelial quiescence by limiting EC glycolysis and OXPHOS (71). Activation of SIRT1 by treatment with an $\mathrm{NAD}^{+}$precursor during exercise training potentiates the increases in capillary density in mice (67). Interestingly, the effect of $P g c 1 \alpha$ overexpression in myofibers on capillary density also depends on SIRT1 activation in ECs (67). SIRT1 is activated not only by a rise in $\mathrm{NAD}^{+}$during energy depletion, but also by hydrogen sulfide $\left(\mathrm{H}_{2} \mathrm{~S}\right)$. In ECs, the latter is generated by cystathionine $\gamma$-lyase (CGL) during dietary restriction of sulfur amino acids (methionine, cysteine) or upon VEGF stimulation. CGL-derived $\mathrm{H}_{2} \mathrm{~S}$ downregulates endothelial OXPHOS and subsequently increases glucose uptake in an AMPK-dependent but VEGF-independent fashion, leading to an increase in glycolysis-driven EC migration and in EC proliferation through increased biosynthesis of nucleotides via the pentose phosphate pathway (72). These data support a role for glycolytic metabolism in exercise-induced angiogenesis, but future genetic experiments are required to confirm this. Moreover, even though deletion of CGL prevented exercise-induced angiogenesis, these genetic interventions were not restricted to ECs and could therefore be confounded by effects of $\mathrm{H}_{2} \mathrm{~S}$ in other cells residing in skeletal muscle (72). The proposed model on how EC metabolism changes in response to exercise is illustrated in Fig. 2.
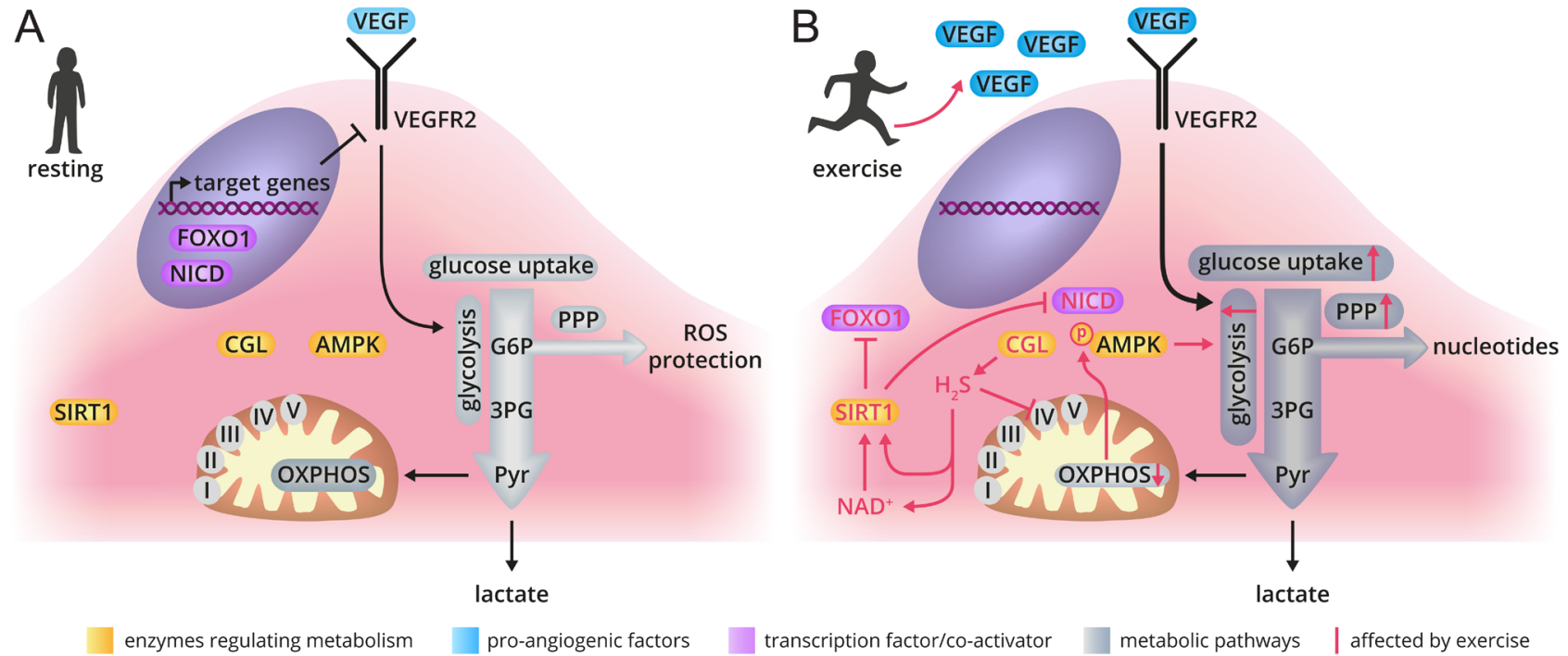

Figure 2

Proposed model for exercise-induced changes in EC metabolism promoting angiogenesis. (Panel A) ECs are highly glycolytic and produce 85\% of their energy glycolytically. Mitochondria do not significantly contribute to energy production but rather maintain NAD+/NADH balance. (Panel B) During exercise, increased CGL activity leads to $\mathrm{H}_{2} \mathrm{~S}$ generation. CGL-derived $\mathrm{H}_{2} \mathrm{~S}$ downregulates endothelial OXPHOS by inhibiting complex IV activity. This leads to increased glucose uptake, glycolysis and pentose phosphate pathway flux in an AMPK-dependent fashion. In addition, exercise-induced angiogenesis requires adequate activation of SIRT1, at least partially because endothelial SIRT1 is required for VEGF-mediated angiogenesis. SIRT1 also controls EC function by inhibiting Notch (NICD indicates active Notch) and via inactivating FOXO1 (forkhead box O1, not shown). 3PG, glyceraldehyde 3-phosphate; AMPK, 5' adenosine monophosphate-activated protein kinase; CGL, cystathionine $\gamma$-lyase; G6P, glucose 6-phosphate; NAD, nicotinamide adenine dinucleotide; NICD, Notch intracellular domain; OXPHOS, oxidative phosphorylation; PPP, pentose phosphate pathway; Pyr, pyruvate; ROS, reactive oxygen species; SIRT1, Sirtuin 1; VEGF, vascular endothelial growth factor; VEGFR2, vascular endothelial growth factor receptor 2.

(C) 2019 The authors Published by Bioscientifica Ltd

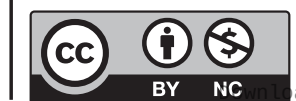

This work is licensed under a Creative Commons Attribution-NonCommercial 4.0 International License. ded from Bioscientifica.com at $04 / 26 / 2023$ 02:14:44PM 


\section{Outlook: can exercise-induced metabolic crosstalk between ECs and muscle contribute to angiogenesis?}

The available evidence thus far indicates that VEGF is driving exercise-induced angiogenesis in skeletal muscle, but the extent of the angiogenic response can be mediated by altering the metabolic 'fitness' of ECs. This raises the exciting hypothesis that targeting EC metabolism can promote exercise-induced angiogenesis. Potentially, skeletal muscle cells can modulate EC metabolic fitness as well via metabolic crosstalk during exercise. Indeed, it has already been shown that metabolites that are secreted from myofibers during exercise can either potentiate the effect of VEGF or directly contribute to angiogenesis. For instance, lactate is secreted (mainly) by fast glycolytic fibers during intense exercise. In other settings, lactate renders ECs more responsive to VEGF by promoting an increase in VEGF receptor content due to enhanced HIF1 $\alpha$ stabilization in an $\alpha$-ketoglutarate- and reactive oxygen species (ROS)dependent fashion $(73,74)$. Increasing lactate levels near ischemic muscles also improves their revascularization (75). Exercising muscles also release ATP, which is converted to adenosine in the extracellular space (76). In the retina, adenosine can act through activation of the adenosine A2a receptor, which causes pathological angiogenesis by increasing endothelial glycolysis in a HIF1 $\alpha$-dependent fashion (77). Whether lactate- and/or adenosine-dependent metabolic rewiring of ECs contributes to exercise-induced angiogenesis remains an open question.

Finally, despite the strong correlation between muscle capillary density and skeletal muscle metabolism (15), as well as the control of Vegf (and other angiogenic factors) expression by myofiber metabolic master switches, there is still no conclusive evidence that improving vascular density is required for achieving muscle adaptations to training, such as increased oxidative capacity and improved performance. On the other hand, the observation that increased capillary density per se (via the overexpression of SIRT1 in ECs) improves running performance and lowers blood glucose levels in mice (67) indicates that increasing blood vessel density suffices to enhance exercise performance and/or affect systemic metabolism. Unraveling the mechanisms underlying these observations will yield valuable insight into metabolic regulation as well as determinants of human performance and will potentially open novel avenues for the treatment of diseases such as peripheral artery disease and insulin resistance.

\section{Declaration of interest}

The authors declare that there is no conflict of interest that could be perceived as prejudicing the impartiality of this review.

\section{Funding}

The research of K D B has received funding from the European Research Council (ERC) under the grant agreement number 716140. K D B is endowed by the Schulthess Foundation.

\section{Acknowledgements}

The authors apologize to all colleagues whose work could not be cited due to space limitations. We thank Marie-Francine Lagadec for translating our ideas and sketches into figures.

\section{References}

1 DeFronzo RA, Jacot E, Jequier E, Maeder E, Wahren J \& Felber JP. The effect of insulin on the disposal of intravenous glucose. Results from indirect calorimetry and hepatic and femoral venous catheterization. Diabetes 198130 1000-1007. (https://doi.org/10.1016/j. cja.2015.03.007)

2 Meyer C, Dostou JM, Welle SL \& Gerich JE. Role of human liver, kidney, and skeletal muscle in postprandial glucose homeostasis. American Journal of Physiology: Endocrinology and Metabolism 2002282 E419-E427. (https://doi.org/10.1152/ajpendo.00032.2001)

3 Ahlborg G, Felig P, Hagenfeldt L, Hendler R \& Wahren J. Substrate turnover during prolonged exercise in man. Journal of Clinical Investigation 197453 1080-1090. (https://doi.org/10.1172/ JCI107645)

4 Egan B \& Zierath JR. Exercise metabolism and the molecular regulation of skeletal muscle adaptation. Cell Metabolism $2013 \mathbf{1 7}$ 162-184. (https://doi.org/10.1016/j.cmet.2012.12.012)

5 Murrant CL \& Sarelius IH. Coupling of muscle metabolism and muscle blood flow in capillary units during contraction. Acta Physiologica Scandinavica 2000168 531-541. (https://doi. org/10.1046/j.1365-201X.2000.00706.x)

6 Kindig CA, Richardson TE \& Poole DC. Skeletal muscle capillary hemodynamics from rest to contractions: implications for oxygen transfer. Journal of Applied Physiology 200292 2513-2520. (https:// doi.org/10.1152/japplphysiol.01222.2001)

7 Clifford PS \& Hellsten Y. Vasodilatory mechanisms in contracting skeletal muscle. Journal of Applied Physiology 200497 393-403. (https://doi.org/10.1152/japplphysiol.00179.2004)

8 Bloor CM. Angiogenesis during exercise and training. Angiogenesis 20058 263-271. (https://doi.org/10.1007/s10456-005-9013-x)

9 Potente M, Gerhardt H \& Carmeliet P. Basic and therapeutic aspects of angiogenesis. Cell 2011146 873-887. (https://doi. org/10.1016/j.cell.2011.08.039)

10 Waters RE, Rotevatn S \& Li P, Annex BH \& Yan Z. Voluntary running induces fiber type-specific angiogenesis in mouse skeletal muscle. American Journal Physiologia Physiologia 2004287 C1342-C1348.

11 Andersen P \& Henriksson J. Capillary supply of the quadriceps femoris muscle of man: adaptive response to exercise. Journal of Physiology 1977 270 677-690. (https://doi.org/10.1113/jphysiol.1977. sp011975)

12 Skorjanc D, Jaschinski F, Heine G \& Pette D. Sequential increases in capillarization and mitochondrial enzymes in low-frequency- (c) 2019 The authors Published by Bioscientifica Ltd



This work is licensed under a Creative Commons Attribution-NonCommercial 4.0 International License. ded from Bioscientifica.com at $04 / 26 / 2023$ 02:14:44PM 
stimulated rabbit muscle. American Journal of Physiology 1998274 C810-C818. (https://doi.org/10.1152/ajpcell.1998.274.3.C810)

13 Hamburg NM \& Balady GJ. Exercise rehabilitation in peripheral artery disease: functional impact and mechanisms of benefits. Circulation 2011123 87-97. (https://doi.org/10.1161/ CIRCULATIONAHA.109.881888)

14 Haas TL, Lloyd PG, Yang HT \& Terjung RL. Exercise training and peripheral arterial disease. Comprehensive Physiology 20122 2933-3017. (https://doi.org/10.1002/cphy.c110065)

$15 \mathrm{Krogh}$ A. The number and distribution of capillaries in muscles with calculations of the oxygen pressure head necessary for supplying the tissue. Journal of Physiology 191952 409-415. (https://doi. org/10.1113/jphysiol.1919.sp001839)

16 Adams RH \& Alitalo K. Molecular regulation of angiogenesis and lymphangiogenesis. Nature Reviews Molecular: Cell Biology 20078 464-478. (https://doi.org/10.1038/nrm2183)

17 Gerhardt H, Golding M, Fruttiger M, Ruhrberg C, Lundkvist A, Abramsson A, Jeltsch M, Mitchell C, Alitalo K, Shima D, et al. VEGF guides angiogenic sprouting utilizing endothelial tip cell filopodia. Journal of Cell Biology 2003161 1163-1177. (https://doi.org/10.1083/ jcb.200302047)

18 Hellstrom M, Phng L, Hofmann JJ, Wallgard E, Coultas L, Lindblom P, Alva J, Nilsson A, Karlsson L, Gaiano N, et al. Dll4 signalling through Notch1 regulates formation of tip cells during angiogenesis. Nature 2007445 776-780. (https://doi.org/10.1038/ nature05571)

19 Mazzone M, Dettori D, de Oliveira RL, Loges S, Schmidt T, Jonckx B, Tian YM, Lanahan AA, Pollard P, de Almodovar CR, et al. Heterozygous deficiency of PHD2 restores tumor oxygenation and inhibits metastasis via endothelial normalization. Cell 2009136 839-851. (https://doi.org/10.1016/j.cell.2009.01.020)

20 Myrhage R \& Hudlická O. Capillary growth in chronically stimulated adult skeletal muscle as studied by intravital microscopy and histological methods in rabbits and rats. Microvascular Research 197816 73-90. (https://doi. org/10.1016/0026-2862(78)90046-8)

21 Egginton S, Hudlicka O, Brown MD, Graciotti L \& Granata AL. In vivo pericyte-endothelial cell interaction during angiogenesis in adult cardiac and skeletal muscle. Microvascular Research $1996 \mathbf{5 1}$ 213-228. (https://doi.org/10.1006/mvre.1996.0022)

22 Hansen-Smith FM, Hudlicka O \& Egginton S. In vivo angiogenesis in adult rat skeletal muscle: early changes in capillary network architecture and ultrastructure. Cell and Tissue Research 1996286 123-136. (https://doi.org/10.1007/s004410050681)

23 Egginton S, Zhou AL, Brown MD \& Hudlická O. Unorthodox angiogenesis in skeletal muscle. Cardiovascular Research 200149 634-646. (https://doi.org/10.1016/S0008-6363(00)00282-0)

24 Williams JL, Cartland D, Rudge JS \& Egginton S. VEGF Trap abolishes shear stress- and overload-dependent angiogenesis in skeletal muscle. Microcirculation 200613 499-509. (https://doi. org/10.1080/10739680600785717)

25 Baum O, Gübeli J, Frese S, Torchetti E, Malik C, Odriozola A, Graber F, Hoppeler H \& Tschanz SA. Angiogenesis-related ultrastructural changes to capillaries in human skeletal muscle in response to endurance exercise. Journal of Applied Physiology 2015 119 1118-1126. (https://doi.org/10.1152/japplphysiol.00594.2015)

26 Geudens I \& Gerhardt H. Coordinating cell behaviour during blood vessel formation. Development 2011138 4569-4583. (https://doi. org/10.1242/dev.062323)

27 Eelen G, De Zeeuw P, Simons M \& Carmeliet P. Endothelial cell metabolism in normal and diseased vasculature. Circulation Research 2015116 1231-1244. (https://doi.org/10.1161/ CIRCRESAHA.116.302855)

28 Potente M \& Mäkinen T. Vascular heterogeneity and specialization in development and disease. Nature Reviews: Molecular Cell Biology 2017 18 477-494. (https://doi.org/10.1038/nrm.2017.36)
29 Gianni-Barrera R, Trani M, Fontanellaz C, Heberer M, Djonov V, Hlushchuk R \& Banfi A. VEGF over-expression in skeletal muscle induces angiogenesis by intussusception rather than sprouting. Angiogenesis 2013 16 123-136. (https://doi.org/10.1007/s10456-012-9304-y)

30 Mentzer SJ \& Konerding MA. Intussusceptive angiogenesis: expansion and remodeling of microvascular networks. Angiogenesis 201417 499-509. (https://doi.org/10.1007/s10456-014-9428-3)

31 Cornachione A, Cação-Benedini LO, Martinez EZ, Neder L \& Cláudia Mattiello-Sverzut A. Effects of eccentric and concentric training on capillarization and myosin heavy chain contents in rat skeletal muscles after hindlimb suspension. Acta Histochemica 2011113 277-282. (https://doi.org/10.1016/j.acthis.2009.10.009)

32 Osada T \& Rådegran G. Difference in muscle blood flow fluctuations between dynamic and static thigh muscle contractions: how to evaluate exercise blood flow by Doppler ultrasound. Physical Medicine and Rehabilitation Research 20171 1-7. (https://doi.org/10.15761/ pmrr.1000128)

33 Breen EC, Johnson EC, Wagner H, Tseng HM, Sung LA \& Wagner PD. Angiogenic growth factor mRNA responses in muscle to a single bout of exercise. Journal of Applied Physiology $1996 \mathbf{8 1}$ 355-361. (https://doi.org/10.1152/jappl.1996.81.1.355)

34 Olenich SA, Gutierrez-Reed N, Audet GN \& Olfert IM. Temporal response of positive and negative regulators in response to acute and chronic exercise training in mice. Journal of Physiology 2013591 5157-5169. (https://doi.org/10.1113/jphysiol.2013.254979)

35 Delavar H, Nogueira L, Wagner PD, Hogan MC, Metzger D \& Breen EC. Skeletal myofiber VEGF is essential for the exercise training response in adult mice. American Journal of Physiology: Regulatory, Integrative and Comprehensive Physiology 2014306 R586-R595.

36 Olfert IM, Howlett RA, Wagner PD \& Breen EC. Myocyte vascular endothelial growth factor is required for exercise-induced skeletal muscle angiogenesis. American Journal of Physiology: Regulatory, Integrative and Comprehensive Physiology 2010299 R1059-R1067. (https://doi.org/10.1152/ajpregu.00347.2010)

37 Gianni-Barrera R, Butschkau A, Uccelli A, Certelli A, Valente P, Bartolomeo M, Groppa E, Burger MG, Hlushchuk R, Heberer M, et al. PDGF-BB regulates splitting angiogenesis in skeletal muscle by limiting VEGF-induced endothelial proliferation. Angiogenesis 2018 21 883-900. (https://doi.org/10.1007/s10456-018-9634-5)

38 Huey KA, Smith SA, Sulaeman A \& Breen EC. Skeletal myofiber VEGF is necessary for myogenic and contractile adaptations to functional overload of the plantaris in adult mice. Journal of Applied Physiology 2016120 188-195. (https://doi.org/10.1152/ japplphysiol.00638.2015)

39 Knapp AE, Goldberg D, Delavar H, Trisko BM, Tang K, Hogan MC, Wagner PD \& Breen EC. Skeletal myofiber VEGF regulates contraction-induced perfusion and exercise capacity but not muscle capillarity in adult mice. American Journal of Physiology: Regulatory, Integrative and Comparative Physiology 2016311 R192-R199. (https:// doi.org/10.1152/ajpregu.00533.2015)

40 Latroche C, Weiss-Gayet M, Muller L, Gitiaux C, Leblanc P, Liot S, Ben-Larbi S, Abou-Khalil R, Verger N, Bardot P, et al. Coupling between myogenesis and angiogenesis during skeletal muscle regeneration is stimulated by restorative macrophages. Stem Cell Reports 20179 2018-2033. (https://doi.org/10.1016/j. stemcr.2017.10.027)

41 Ripoll E, Sillau AH \& Banchero N. Changes in the capillarity of skeletal muscle in the growing rat. Pflugers Archiv 1979380 153-158. (https://doi.org/10.1007/BF00582151)

42 Ingjer F. Capillary supply and mitochondrial content of different skeletal muscle fiber types in untrained and endurance-trained men. A histochemical and ultrastructural study. European Journal of Applied Physiology and Occupational Physiology 197940 197-209. (https://doi. org/10.1007/BF00426942)

43 Narkar VA, Fan W, Downes M, Yu RT, Jonker JW, Alaynick WA, Banayo E, Karunasiri MS, Lorca S \& Evans RM. Exercise and 
PGC-1 $\alpha$-independent synchronization of type i muscle metabolism and vasculature by ERR $\gamma$. Cell Metabolism 201113 283-293. (https:// doi.org/10.1016/j.cmet.2011.01.019)

44 Ouchi N, Shibata R \& Walsh K. AMP-activated protein kinase signaling stimulates VEGF expression and angiogenesis in skeletal muscle. Circulation Research 200596 838-846. (https://doi. org/10.1161/01.RES.0000163633.10240.3b)

45 Zwetsloot KA, Westerkamp LM, Holmes BF \& Gavin TP. AMPK regulates basal skeletal muscle capillarization and VEGF expression, but is not necessary for the angiogenic response to exercise. Journal of Physiology 2008586 6021-6035. (https://doi.org/10.1113/ jphysiol.2008.159871)

46 Pilegaard H, Saltin B \& Neufer PD. Exercise induces transient transcriptional activation of the PGC-1 $\alpha$ gene in human skeletal muscle. Journal of Physiology 2003546 851-858. (https://doi. org/10.1113/jphysiol.2002.034850)

47 Silvennoinen M, Ahtiainen JP, Hulmi JJ, Pekkala S, Taipale RS, Nindl BC, Laine T, Häkkinen K, Selänne H, Kyröläinen H, et al. PGC-1 isoforms and their target genes are expressed differently in human skeletal muscle following resistance and endurance exercise. Physiological Reports 20153 e12563. (https://doi.org/10.14814/ phy2.12563)

$48 \mathrm{Wu}$ Z, Puigserver P, Andersson U, Zhang C, Adelmant G, Mootha V, Troy A, Cinti S, Lowell B, Scarpulla RC, et al. Mechanisms controlling mitochondrial biogenesis and respiration through the thermogenic coactivator PGC-1. Cell 199998 115-124. (https://doi.org/10.1016/ S0092-8674(00)80611-X)

49 Arany Z, Foo SY, Ma Y, Ruas JL, Bommi-Reddy A, Girnun G, Cooper M, Laznik D, Chinsomboon J, Rangwala SM, et al. HIF-independent regulation of VEGF and angiogenesis by the transcriptional coactivator PGC-1 $\alpha$. Nature 2008451 1008-1012. (https://doi.org/10.1038/nature06613)

50 Chinsomboon J, Ruas J, Gupta RK, Thom R, Shoag J, Rowe GC, Sawada N, Raghuram S \& Arany Z. The transcriptional coactivator PGC-1 $\alpha$ mediates exercise-induced angiogenesis in skeletal muscle. PNAS 2009106 21401-21406. (https://doi.org/10.1073/ pnas.0909131106)

51 Fan W, He N, Lin CS, Wei Z, Hah N, Waizenegger W, He MX, Liddle C, Yu RT, Atkins AR, et al. ERR $\gamma$ promotes angiogenesis, mitochondrial biogenesis, and oxidative remodeling in PGC $1 \alpha / \beta$ deficient muscle. Cell Reports 201822 2601-2614.

52 Geng T, Li P, Okutsu M, Yin X, Kwek J, Zhang M \& Yan Z. PGC$1 \alpha$ plays a functional role in exercise-induced mitochondrial biogenesis and angiogenesis but not fiber-type transformation in mouse skeletal muscle. American Journal of Physiology: Cell Physiology 2010298 C572-C579. (https://doi.org/10.1152/ ajpcell.00481.2009)

53 Thom R, Rowe GC, Jang C, Safdar A \& Arany Z. Hypoxic induction of vascular endothelial growth factor (VEGF) and angiogenesis in muscle by truncated peroxisome proliferator-activated receptor $\gamma$ coactivator (PGC)-1 $\alpha$. Journal of Biological Chemistry 2014289 8810-8817. (https://doi.org/10.1074/jbc.M114.554394)

54 O'Hagan KA, Cocchiglia S, Zhdanov AV, Tambuwala MM, Cummins EP, Monfared M, Agbor TA, Garvey JF, Papkovsky DB, Taylor CT, et al. PGC-1 is coupled to HIF-1 -dependent gene expression by increasing mitochondrial oxygen consumption in skeletal muscle cells. PNAS 2009106 2188-2193. (https://doi. org/10.1073/pnas.0808801106)

55 Mason SD, Rundqvist H, Papandreou I, Duh R, McNulty WJ, Howlett RA, Olfert IM, Sundberg CJ, Denko NC, Poellinger L, et al. HIF-1 $\alpha$ in endurance training: suppression of oxidative metabolism. American Journal of Physiology: Regulatory, Integrative and Comparative Physiology 2007293 R2059-R2069. (https://doi.org/10.1152/ ajpregu.00335.2007)

56 De Bock K, Georgiadou M, Schoors S, Kuchnio A, Wong BW, Cantelmo AR, Quaegebeur A, Ghesquière B, Cauwenberghs S,
Eelen G, et al. Role of PFKFB3-driven glycolysis in vessel sprouting. Cell 2013154 651-663. (https://doi.org/10.1016/j. cell.2013.06.037)

57 Schoors S, De Bock K, Cantelmo AR, Georgiadou M, Ghesquière B, Cauwenberghs S, Kuchnio A, Wong BW, Quaegebeur A, Goveia J, et al. Partial and transient reduction of glycolysis by PFKFB3 blockade reduces pathological angiogenesis. Cell Metabolism 201419 37-48. (https://doi.org/10.1016/j.cmet.2013.11.008)

58 Yu P, Wilhelm K, Dubrac A, Tung JK, Alves TC, Fang JS, Xie Y, Zhu J, Chen Z, De Smet F, et al. FGF-dependent metabolic control of vascular development. Nature 2017545 224-228. (https://doi. org/10.1038/nature22322)

59 Kim B, Jang C, Dharaneeswaran H, Li J, Bhide M, Yang S, Li K \& Arany Z. Endothelial pyruvate kinase M2 maintains vascular integrity. Journal of Clinical Investigation 2018128 4543-4556. (https://doi.org/10.1172/JCI120912)

60 Diebold LP, Gil HJ, Gao P, Martinez CA, Weinberg SE \& Chandel NS. Mitochondrial complex III is necessary for endothelial cell proliferation during angiogenesis. Nature Metabolism 20191 158-171. (https://doi.org/10.1038/s42255-018-0011-x)

61 Schoors S, Bruning U, Missiaen R, Queiroz KC, Borgers G, Elia I, Zecchin A, Cantelmo AR, Christen S, Goveia J, et al. Fatty acid carbon is essential for dNTP synthesis in endothelial cells. Nature $2015 \mathbf{5 2 0}$ 192-197. (https://doi.org/10.1038/nature14362)

62 Bruning U, Morales-Rodriguez F, Kalucka J, Goveia J, Taverna F, Queiroz KCS, Dubois C, Cantelmo AR, Chen R, Loroch S, et al. Impairment of angiogenesis by fatty acid synthase inhibition involves mTOR malonylation. Cell Metabolism 201828 866-880.e15. (https://doi.org/10.1016/j.cmet.2018.07.019)

63 Huang H, Vandekeere S, Kalucka J, Bierhansl L, Zecchin A, Brüning U, Visnagri A, Yuldasheva N, Goveia J, Cruys B, et al. Role of glutamine and interlinked asparagine metabolism in vessel formation. EMBO Journal 201736 2334-2352. (https://doi. org/10.15252/embj.201695518)

64 Kim B, Li J, Jang C \& Arany Z. Glutamine fuels proliferation but not migration of endothelial cells. EMBO Journal 201736 2321-2333. (https://doi.org/10.15252/embj.201796436)

65 Fitzgerald G, Soro-Arnaiz I \& De Bock K. The Warburg effect in endothelial cells and its potential as an anti-angiogenic target in cancer. Frontiers in Cell and Developmental Biology 20186100. (https://doi.org/10.3389/fcell.2018.00100)

66 Eelen G, de Zeeuw P, Treps L, Harjes U, Wong BW \& Carmeliet P. Endothelial cell metabolism. Physiological Reviews 201898 3-58. (https://doi.org/10.1152/physrev.00001.2017)

67 Das A, et al. Impairment of an endothelial NAD+-H2S signaling network is a reversible cause of vascular aging. Cell 2018173 e20.

68 Potente M, Ghaeni L, Baldessari D, Mostoslavsky R, Rossig L, Dequiedt F, Haendeler J, Mione M, Dejana E, Alt FW, et al. SIRT1 controls endothelial angiogenic functions during vascular growth Genes and Development 200721 2644-2658. (https://doi.org/10.1101/ gad.435107)

69 Guarani V, Deflorian G, Franco CA, Krüger M, Phng L, Bentley K, Toussaint L, Dequiedt F, Mostoslavsky R, Schmidt MHH, et al. Acetylation-dependent regulation of endothelial Notch signalling by the SIRT1 deacetylase. Nature 2011473 234-238. (https://doi. org/10.1038/nature09917)

70 Dimova I, Hlushchuk R, Makanya A, Styp-Rekowska B, Ceausu A, Flueckiger S, Lang S, Semela D, Le Noble F, Chatterjee S, et al. Inhibition of Notch signaling induces extensive intussusceptive neo-angiogenesis by recruitment of mononuclear cells. Angiogenesis 201316 921-937. (https://doi.org/10.1007/s10456-013-9366-5)

71 Wilhelm K, Happel K, Eelen G, Schoors S, Oellerich MF, Lim R, Zimmermann B, Aspalter IM, Franco CA, Boettger T, et al. FOXO1 couples metabolic activity and growth state in the vascular endothelium. Nature 2016529 216-220. (https://doi.org/10.1038/ nature16498) 
72 Longchamp A, Mirabella T, Arduini A, MacArthur MR, Das A, Treviño-Villarreal JH, Hine C, Ben-Sahra I, Knudsen NH, Brace LE, et al. Amino acid restriction triggers angiogenesis via GCN2/ATF4 regulation of VEGF and H2S production. Cell 2018173 117.e14-129. e14. (https://doi.org/10.1016/j.cell.2018.03.001)

73 Végran F, Boidot R, Michiels C, Sonveaux P \& Feron O. Lactate influx through the endothelial cell monocarboxylate transporter MCT1 supports an NF-kB/IL-8 pathway that drives tumor angiogenesis. Cancer Research 201171 2550-2560. (https://doi.org/10.1158/00085472.CAN-10-2828)

74 Sonveaux P, Copetti T, De Saedeleer CJ, Végran F, Verrax J, Kennedy KM, Moon EJ, Dhup S, Danhier P, Frérart F, et al. Targeting the lactate transporter MCT1 in endothelial cells inhibits lactate-induced HIF-1 activation and tumor angiogenesis.
PLOS ONE 20127 e33418. (https://doi.org/10.1371/journal. pone.0033418)

75 Porporato PE, Payen VL, De Saedeleer CJ, Préat V, Thissen JP, Feron O \& Sonveaux P. Lactate stimulates angiogenesis and accelerates the healing of superficial and ischemic wounds in mice. Angiogenesis 201215 581-592. (https://doi.org/10.1007/s10456-012-9282-0)

76 Adair TH. Growth regulation of the vascular system: an emerging role for adenosine. American Journal of Physiology: Regulatory, Integrative and Comprehensive Physiology 2005289 R283-R296. (https://doi.org/10.1152/ajpregu.00840.2004)

77 Liu Z, Yan S, Wang J, Xu Y, Wang Y, Zhang S, Xu X, Yang Q, Zeng X, Zhou Y, et al. Endothelial adenosine A2a receptor-mediated glycolysis is essential for pathological retinal angiogenesis. Nature Communications 20178 584. (https://doi.org/10.1038/s41467-017-00551-2)

Received in final form 19 February 2019

Accepted 11 March 2019

Accepted Preprint published online 11 March 2019 (c) 2019 The authors Published by Bioscientifica Ltd



This work is licensed under a Creative Commons Attribution-NonCommercial 4.0 International License. 